\title{
Optimization and evaluation of cyclosporine A nanosuspension stabilized by combination stabilizers using high pressure homogenization method
}

\author{
Sıla GÜLBAĞ PINAR ${ }^{1}$ (D), Nevin ÇELEBİ 1 * (D) \\ 1 Department of Pharmaceutical Technology, Faculty of Pharmacy, Gazi University, Ankara, Turkey. \\ * Corresponding Author. E-mail: ncelebi51@gmail.com (N.C.); Tel. +90-533-324 3313.
}

Received: 29 May 2019 / Revised: 11 July 2019/ Accepted: 31 July 2019

\begin{abstract}
The purpose of this study was to develop Cyclosporine A (CsA) nanosuspension by using different stabilizers for oral administration. CsA nanosuspension was prepared by high pressure homogenization technology and HPMC and Soluplus ${ }^{\circledR}$ combination were selected as stabilizers. After Design of Experiment (DoE) analysis, optimum formulation was selected and characterized by particle size (PS), particle size distribution (PDI) and zeta potential (ZP) measurements. Scanning electron microscopy (SEM), differential scanning calorimetry (DSC), X-ray diffraction (X-RD), and fourier transform infrared (FTIR) analysis were also performed. Solubility studies were done with optimum lyophilised CsA nanosuspension. The results revealed that appropriate PS, PDI, and ZP results were not obtained with the use of stabilizers separately in preformulation studies. Optimum stabilizers ratio was determined CsA:HPMC:Soluplus ${ }^{\circledR}$ 1:1:0.5 $(\mathrm{w} / \mathrm{w})$ in nanosuspension formulation after DoE. It was found to be appropriate with a small particle size of $366.8 \pm 9.6 \mathrm{~nm}$, a narrow particle size distribution of $0.48 \pm 0.02$, and a negative zeta potential value of $-14.4 \pm 0.4 \mathrm{mV}$ after 30 homogenization cycles. In solubility study, the CsA solubility in the nanosuspension was increased up to 2.1 times in comparison with the coarse CsA. CsA nanosuspension showed a short-term stability over the examined period of one month. CsA nanosuspension can be successfully produced by Microfluidics with HPMC:Soluplus ${ }^{\circledR}$ combination as stabilizers using DoE approach.
\end{abstract}

KEYWORDS: Cyclosporine; nanosuspension; high pressure homogenization; HPMC; Soluplus ${ }^{\circledR}$.

\section{INTRODUCTION}

Cyclosporine A (CsA) was approved by the US Food and Drug Administration (FDA) and the European Medicines Agency (EMA), after being found to be effective in immunosuppression in 1980. Cyclosporine A, which is composed of 11 amino acids and is a neutral cyclic polypeptide; is one of the most commonly used immunosuppressants for the prevention of organ rejection after transplantation [1]. CsA binds to cyclophilin and forms cyclosporin-cyclophilin complex and exhibits immunosuppressive activity by inhibiting T-cell activation and calcineurin phosphatase [2]. CsA is considered to be Biopharmaceutical Classification System (BCS) Class II drug because of its low water solubility and low dissolution rate and bioavailability after oral administration.

Nanosuspension (or nanocrystal) technology; is an interesting approach used to increase the solubility, dissolution and thus bioavailability of BCS Class II and IV drugs by reducing (nanonizing) the particle size of nanoparticles to nanoscale dimensions without any carrier $[3,4,5]$. Nanosuspensions have many advantages such as increased rate of absorption, increased oral bioavailability, reduction in fed/fasted variability, improved stability, low cost of production, and ease of scale up [6,7]. As a result of these advantages of this technology, it has been introduced to commercial products with nanosuspension-based formulations in different drugs which have different indications, such as sirolimus (Rapamune $\left.{ }^{\circledR}\right)$, aprepitant $\left(\right.$ Emend $\left.^{\circledR}\right)$, fenofibrate $\left(\right.$ Tricor $\left.^{\circledR}\right)$, fenofibrate (Triglide ${ }^{\circledR}$ ), and megesterol acetate (Megace ES ${ }^{\circledR}$ ) [8]. Nanosuspensions can be prepared by two approaches; top down and bottom up production. In the top down production, while the particles of the large drug molecules are reduced to nano sizes by using media milling, microfluidization, and high pressure homogenization while the bottom up production achieves the nanoscale particle size by

How to cite this article: Gülbağ-Pınar S, Çelebi N. Optimization and evaluation of cyclosporine A nanosuspension stabilized by combination stabilizers using high pressure homogenization method. J Res Pharm. 2019; 23(6): 1009-1021. 
nanoprecipitation using the molecule dissolved in the organic solvent $[9,10]$. There are many publications about microfluidization $[11,12$, 13], high pressure homogenization $[14,15,16]$, media milling $[17,18,19,20$, $21,22]$ and precipitation [23, 24, 25,26]. Due to numerous advantages of top down production methods, such as using of minimum of organic solvent and solvent residues, higher drug capacity (approximately 100\%), stability of formulation, they are considered as the first alternative of nanosuspension formulation and therefore there are many studies on the combined use of these top down technologies in publications [27, 28, 29]. High pressure homogenization can be explained in two different classes for homogenization principle and homogenizer type: a) Piston Gap homogenization method, b) Microfluidization technology. In high pressure homogenisation method with microfluidization technology with $\mathrm{Z}$ or $\mathrm{Y}$ type chambers, particle size is reduced by cavitation of high pressure applied on 1700 bar. For adequate particle size reduction, 50-100 cycles should be applied [30]. In a study conducted with ritonavir, which is an active substance with low solubility in water, ritonavir (RTV) nanosuspensions were developed successfully by microfluidization method using DoE. The parameters affecting the product quality were determined and the RTV: HPMC: SDS (1:2:0.4) ratio was found to be the optimum formulation after 20 homogenization cycles. In the in vitro dissolution rate studies, an increase in the solubility and dissolution rate of RTV was observed [12]. Also, the combination of two preparation methods, which are microprecipitation and high-pressure homogenization technologies, is widely used currently $[31,32,33,34,35]$. As a result of this combination technology, NanoEdge ${ }^{\circledR}$ is obtained [36].

In the light of this information given above, the possibility of preparing CsA nanosuspension for oral application with different stabilizers seperately and combination of stabilizers were investigated by using microfluidizer (high pressure homogenization method) which is one of the nanosuspension production methods using DoE approach. Characterization studies of the obtained optimum nanosuspension formulation were performed and the saturated solubility of CsA coarse powder and CsA nanosuspension in water was investigated.

\section{RESULTS AND DISCUSSION}

\subsection{Particle size, particle size distribution and zeta potential}

Particle size (PS), particle size distribution (PDI) and zeta potential (ZP) values are the most important physical properties of colloidal systems, such as nanosuspensions. It is very significant to reduce the particle size in low solubility drugs, which are classified as BCS Class II and IV. The smaller particle size increases the solubility and bioavailability of active ingredients. When the preparation of nanosuspension with high pressure homogenization technique, the particle size is reduced and the surface area is increased. The acceptable values for PS, PDI, and ZP of nanosuspensions are nanometer size, $<0.5$, and $\sim-20 \mathrm{mv}$, respectively. Increased zeta potential values indicate that the formulation has good physical stability. Therefore, PS, PDI, and ZP results were used to decide on the most appropriate nanosuspension formulation [37]. PS, PDI, and $\mathrm{ZP}$ measurement results (at the beginning) of prepared nanosuspension with stabilizers are shown in Table 1 and 2.

In the formulation prepared by using HPMC, one of the most commonly used stabilizers in the preparation of nanosuspension, when the number of cycles was increased from 5 to 30, the particle size decreased, but this reduction was not seen as a nanometer. Also, when the number of cycles was increased, the particle size distribution decreased, which indicated that the particle size distribution became more homogeneous. The zeta potential values for all ratios remained approximately $-15 \mathrm{mV}$. These results indicated that formulation including only HPMC was not a suitable stabilizer for preparing CsA nanosuspension by using high pressure homogenization (Table 1).

According to the results given in Table 1, all the formulations prepared with Soluplus ${ }^{\circledR}$ were in nanometer size between $115.5 \pm 10.2 \mathrm{~nm}$ and $328.5 \pm 10.8 \mathrm{~nm}$. The mean particle size distribution values of all ratios were over 0.5 (PDI) and it was very high when evaluated in terms of nanosuspension formulations.

The above-mentioned formulation studies with both stabilizers predicted that the combined use of these two stabilizers (HPMC and Soluplus ${ }^{\circledR}$ ) could provide lower particle size, lower particle size distribution, and higher zeta potential. For this purpose, the use of HPMC with a $1 \%$ ratio and a small amount of Soluplus ${ }^{\circledR}$ was thought to reduce the particle size and provide optimum zeta potential for long term stabilization. CsA:HPMC:Soluplus ${ }^{\circledR}$ ratios were determined as 1:1:0.5 and 1:1:0.25 and further formulation studies were performed in these ratios (F7 and F8). As shown in Table 2, nanosuspension with smaller particle size and higher zeta potential were obtained when they were prepared with combination stabilizer and after 30 homogenization cycles. 
Table 1. PS, PDI, and ZP results of the HPMC and Soluplus ${ }^{\circledR}$ stabilized nanosuspensions (at initial).

\begin{tabular}{|c|c|c|c|c|c|c|c|}
\hline \multirow{19}{*}{ 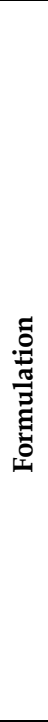 } & & Ratio & Parameter & $\begin{array}{c}\text { After } 5 \text { cycles } \\
(n=3)\end{array}$ & $\begin{array}{c}\text { After } 10 \text { cycles } \\
(n=3)\end{array}$ & $\begin{array}{c}\text { After } 15 \text { cycles } \\
(n=3)\end{array}$ & $\begin{array}{c}\text { After } 30 \text { cycles } \\
(n=3)\end{array}$ \\
\hline & \multirow{9}{*}{ 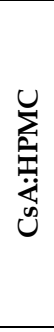 } & \multirow{3}{*}{ 1:4 } & PS (nm) & $2231.3 \pm 146.0$ & $2162.0 \pm 91.7$ & $2256.3 \pm 129.1$ & $1599.0 \pm 55.8$ \\
\hline & & & PDI & $0.50 \pm 0.03$ & $0.48 \pm 0.04$ & $0.47 \pm 0.01$ & $0.42 \pm 0.02$ \\
\hline & & & $\mathrm{ZP}(\mathrm{mV})$ & $-6.5 \pm 0.2$ & $-4.7 \pm 0.2$ & $-4.8 \pm 0.2$ & $-3.8 \pm 0.0$ \\
\hline & & \multirow{3}{*}{ 1:2 } & PS (nm) & $1539.7 \pm 73.3$ & $1177.0 \pm 38.5$ & $1071.3 \pm 10.4$ & $949.5 \pm 14.0$ \\
\hline & & & PDI & $0.46 \pm 0.03$ & $0.35 \pm 0.03$ & $0.42 \pm 0.05$ & $0.36 \pm 0.06$ \\
\hline & & & $\mathrm{ZP}(\mathrm{mV})$ & $-14.8 \pm 0.5$ & $-9.3 \pm 0.1$ & $-12.0 \pm 0.8$ & $-13.9 \pm 0.5$ \\
\hline & & \multirow{3}{*}{ 1:1 } & PS (nm) & $1093.3 \pm 21.5$ & $929.3 \pm 36.8$ & $904.0 \pm 63.6$ & $975.6 \pm 24.3$ \\
\hline & & & PDI & $0.59 \pm 0.07$ & $0.45 \pm 0.06$ & $0.44 \pm 0.03$ & $0.43 \pm 0.01$ \\
\hline & & & $\mathrm{ZP}(\mathrm{mV})$ & $-11.7 \pm 0.2$ & $-12.4 \pm 0.3$ & $-9.0 \pm 0.5$ & $-10.8 \pm 0.4$ \\
\hline & \multirow{9}{*}{ 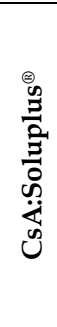 } & \multirow{3}{*}{ 1:4 } & PS (nm) & $120.9 \pm 10.9$ & $115.5 \pm 10.2$ & $116.3 \pm 5.8$ & $126.7 \pm 6.9$ \\
\hline & & & PDI & $0.58 \pm 0.06$ & $0.59 \pm 0.01$ & $0.59 \pm 0.01$ & $0.60 \pm 0.04$ \\
\hline & & & $\mathrm{ZP}(\mathrm{mV})$ & $0.3 \pm 0.5$ & $-5.3 \pm 0.7$ & $-4.2 \pm 0.1$ & $-9.7 \pm 0.5$ \\
\hline & & \multirow{3}{*}{$1: 2$} & PS (nm) & $227.8 \pm 18.4$ & $178.2 \pm 17.5$ & $175.1 \pm 9.9$ & $228.5 \pm 11.7$ \\
\hline & & & PDI & $0.84 \pm 0.13$ & $0.75 \pm 0.00$ & $0.82 \pm 0.04$ & $0.86 \pm 0.03$ \\
\hline & & & $\mathrm{ZP}(\mathrm{mV})$ & $-13.5 \pm 1.1$ & $-7.8 \pm 2.3$ & $-4.3 \pm 1.6$ & $-10.3 \pm 1.1$ \\
\hline & & \multirow{3}{*}{ 1:1 } & PS (nm) & $276.4 \pm 24.1$ & $267.1 \pm 13.3$ & $304.8 \pm 10.0$ & $328.5 \pm 10.8$ \\
\hline & & & PDI & $0.96 \pm 0.07$ & $0.87 \pm 0.05$ & $0.83 \pm 0.09$ & $0.50 \pm 0.04$ \\
\hline & & & $\mathrm{ZP}(\mathrm{mV})$ & $-6.0 \pm 0.3$ & $-4.4 \pm 1.7$ & $-5.6 \pm 1.6$ & $-12.8 \pm 1.1$ \\
\hline
\end{tabular}

The experimental analyis with Design Expert ${ }^{\circledR} 9.0$ showed that interactions between independent variables, homogenization cycles, and Soluplus ${ }^{\circledR}$ ratios were found to be effective on PS, PDI, and ZP values $(\mathrm{p}<0.05)$ (Figure 1). Equations of the models for PS (Eq. 1), PDI (Eq. 2), and ZP (Eq. 3) are given below:

$$
\begin{aligned}
& P S=+606.49-133.29 x A-20.04 x B-47.44 x A B \\
& P D I=+0.63+0.027 x A-0.15 x B-0.025 x A B \\
& Z P=-10.48+0.81 x A-3.25 x B-0.82 x A B
\end{aligned}
$$

Where $\mathrm{A}$ is the Soluplus ${ }^{\circledR}$ ratio, B is the homogenization cycles number, and $\mathrm{AB}$ is the interaction between Soluplus ${ }^{\circledR}$ ratio and homogenization cycles number.

The selection of higher Soluplus ${ }^{\circledR}$ ratio and the increase in the number of homogenization cycles significantly reduced the PS and smaller particle size was obtained by increasing the Soluplus ${ }^{\circledR}$ ratio. Smaller PDI values were obtained in formulations prepared with higher homogenization cycles and all Soluplus ${ }^{\circledR}$ ratios. When higher number of homogenization cycles was used, the ZP values were not affected by the Soluplus ${ }^{\circledR}$ ratio. A significant decrease in particle size of formulation was observed after DoE analysis when

\begin{tabular}{|c|c|c|c|c|c|c|}
\hline & Ratio & Parameter & $\begin{array}{c}\text { After } 5 \text { cycles } \\
(n=3)\end{array}$ & $\begin{array}{c}\text { After } 10 \text { cycles } \\
(n=3)\end{array}$ & $\begin{array}{l}\text { After } 15 \text { cycles } \\
(n=3)\end{array}$ & $\begin{array}{c}\text { After } 30 \text { cycles } \\
(n=3)\end{array}$ \\
\hline \multirow{6}{*}{ 1.Replicate } & \multirow{3}{*}{ 1:1:0.5 } & PS (nm) & $585.2 \pm 50.4$ & $532.4 \pm 38.5$ & $482.6 \pm 36.8$ & $425.1 \pm 29.2$ \\
\hline & & PDI & $0.90 \pm 0.16$ & $0.56 \pm 0.01$ & $0.57 \pm 0.12$ & $0.51 \pm 0.05$ \\
\hline & & $\mathrm{ZP}(\mathrm{mV})$ & $-8.3 \pm 0.7$ & $-7.6 \pm 0.7$ & $-11.4 \pm 0.5$ & $-13.2 \pm 0.7$ \\
\hline & \multirow{3}{*}{ 1:1:0.25 } & PS (nm) & $684.8 \pm 54.4$ & $664.8 \pm 68.6$ & $862.3 \pm 52.5$ & $706.4 \pm 56.6$ \\
\hline & & PDI & $0.81 \pm 0.14$ & $0.57 \pm 0.09$ & $0.62 \pm 0.05$ & $0.49 \pm 0.03$ \\
\hline & & $\mathrm{ZP}(\mathrm{mV})$ & $-8.4 \pm 0.5$ & $-8.9 \pm 0.8$ & $-11.6 \pm 0.3$ & $-13.3 \pm 0.8$ \\
\hline \multirow{6}{*}{ 2.Replicate } & \multirow{3}{*}{ 1:1:0.5 } & PS (nm) & $497.5 \pm 54.4$ & $433.6 \pm 29.9$ & $570.4 \pm 44.6$ & $366.8 \pm 9.6$ \\
\hline & & PDI & $0.91 \pm 0.10$ & $0.71 \pm 0.14$ & $0.88 \pm 0.14$ & $0.48 \pm 0.02$ \\
\hline & & $\mathrm{ZP}(\mathrm{mV})$ & $-3.22 \pm 0.4$ & $-6.53 \pm 2.0$ & $-6.14 \pm 0.8$ & $-14.4 \pm 0.4$ \\
\hline & \multirow{3}{*}{ 1:1:0.25 } & PS (nm) & $824.2 \pm 104.7$ & $713.4 \pm 41.9$ & $557.2 \pm 30.6$ & $861.3 \pm 87.6$ \\
\hline & & PDI & $0.81 \pm 0.15$ & $0.67 \pm 0.14$ & $0.49 \pm 0.01$ & $0.55 \pm 0.12$ \\
\hline & & $\mathrm{ZP}(\mathrm{mV})$ & $-7.96 \pm 0.4$ & $-10.5 \pm 0.2$ & $-12.7 \pm 0.5$ & $-13.1 \pm 0.6$ \\
\hline
\end{tabular}
they were prepared with 1:1:0.5 ratios (Figure 1).

Table 2. PS, PDI, and ZP results of the CsA:HPMC:Soluplus ${ }^{\circledR}$ stabilized nanosuspensions (at initial). 
A

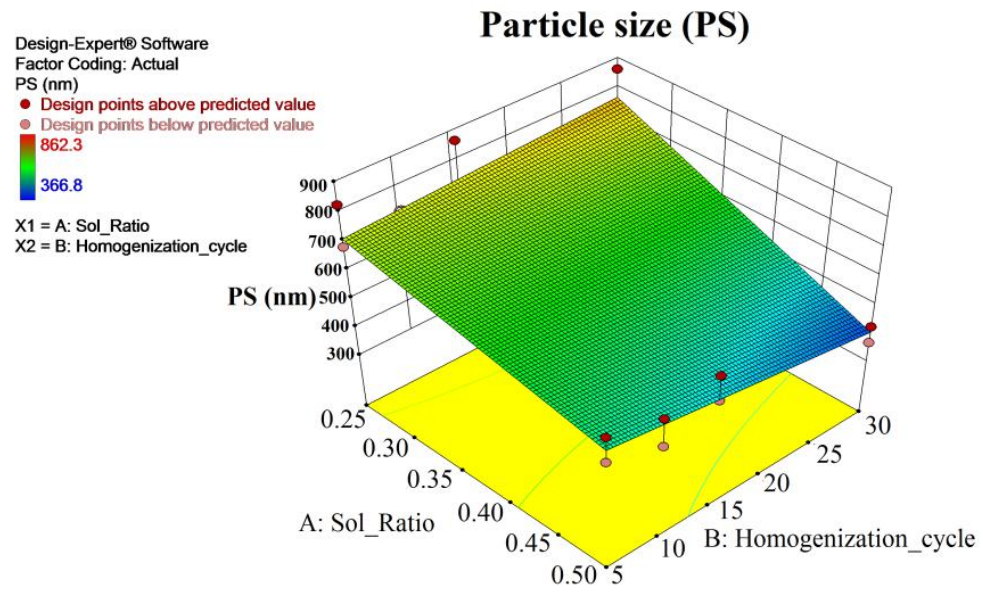

B

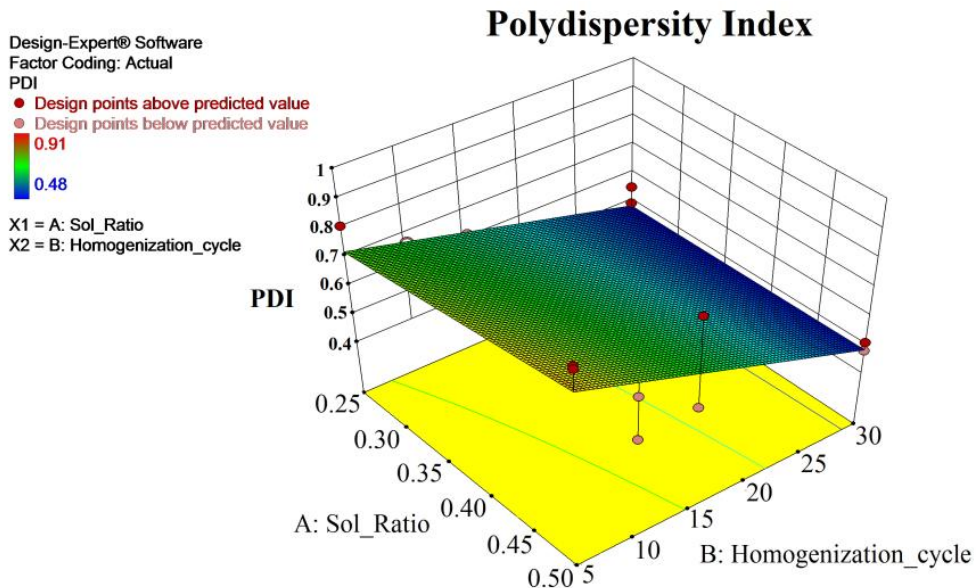

C

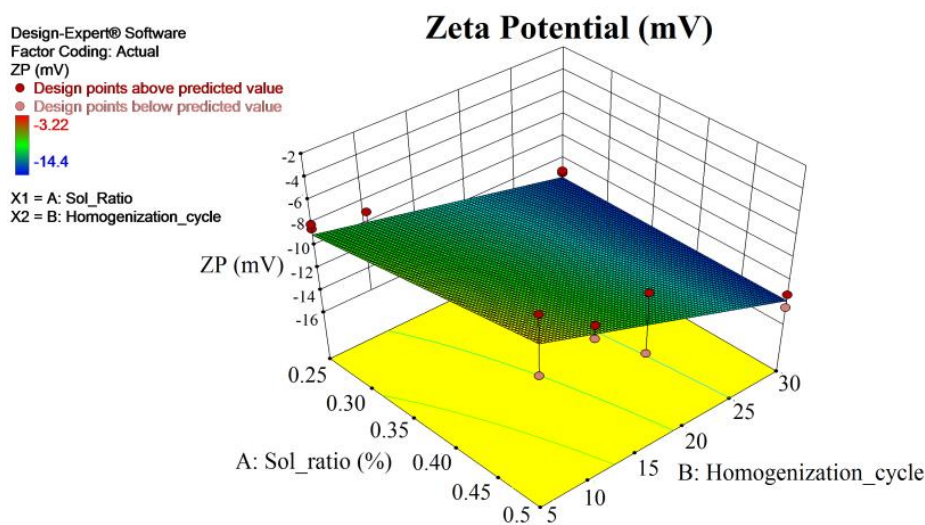

Figure 1. Contour plots indicating the influence of the stabilizer (Soluplus ${ }^{\circledR}$ ) ratios, homogenization cycles on PS (A), PDI (B), and ZP (C).

\subsection{Short term physical stability}

The physical stability, which is caused by Ostwald ripening and the aggregation of particles, is very important for nanosuspension formulations. Acceptable physical short term stability is related to the protection by the stabilizers and homogenization cycles of drugs in nanosuspension formulation. The changes in the particle size and zeta potential of CsA:HPMC:Soluplus ${ }^{\circledR}$ formulation 1:1:0.5 (F7) and 1:1:0.25 (F8) after storage for one week and one month at room temperature are shown in Figure 2 and 3, respectively. 
A

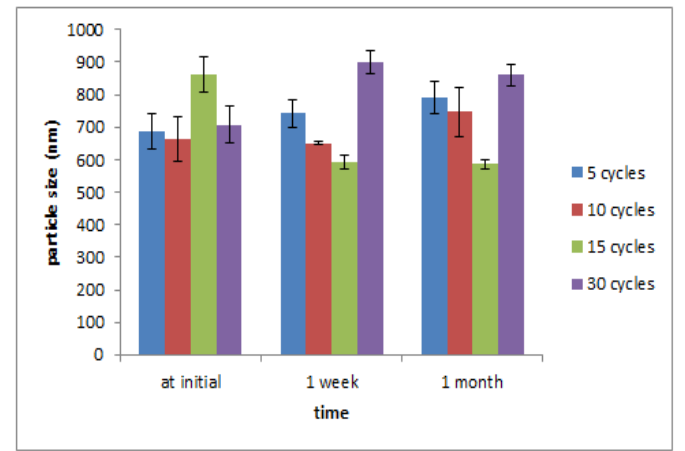

B

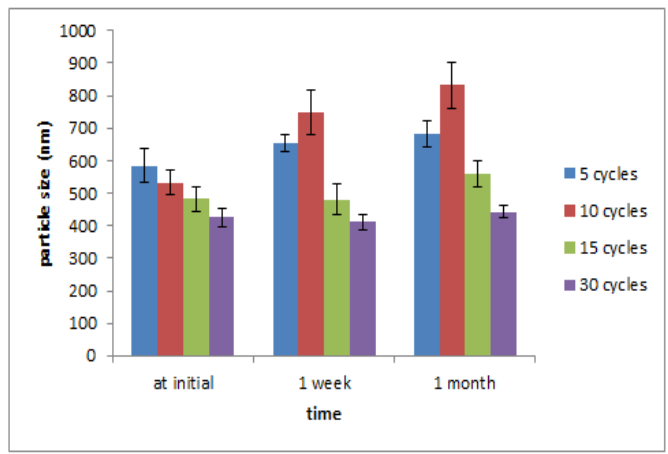

Figure 2. Short term physical stability particle size results of CsA nanosuspensions during 1 month storage at $25^{\circ} \mathrm{C}$. CsA:HPMC:Soluplus ${ }^{\circledR}$ ratios are 1:1:0.25 (A) and 1:1:0.5 (B).

A

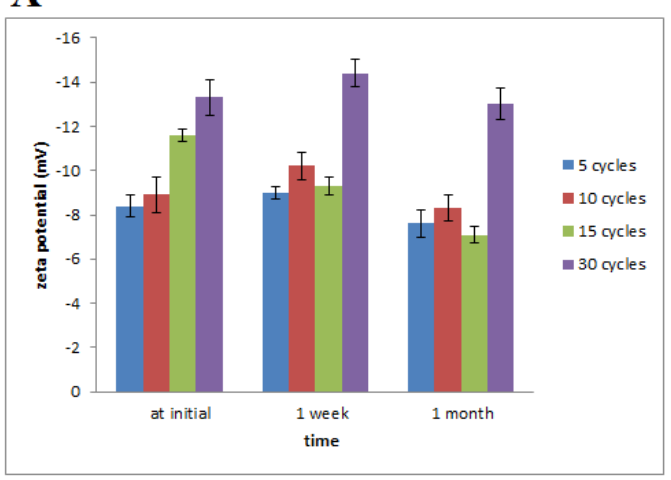

B

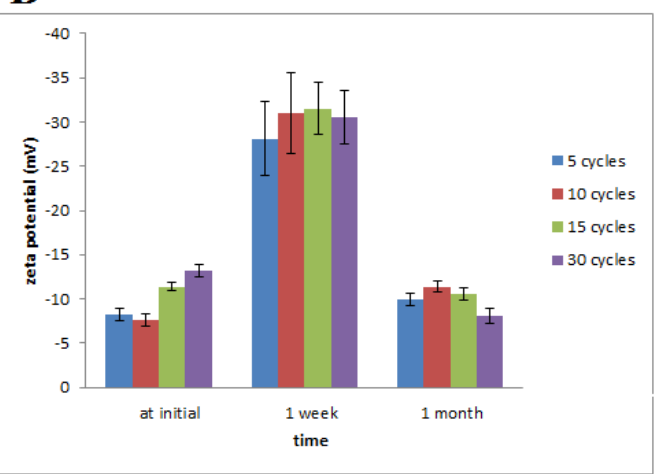

Figure 3. Short term physical stability zeta potential results of CsA nanosuspensions during 1 month storage at $25^{\circ} \mathrm{C}$. CsA:HPMC:Soluplus ${ }^{\circledR}$ ratios are 1:1:0.25 (A) and 1:1:0.5 (B).

The size of F7 formulation after 30 homogenization cycles increased from $425.1 \mathrm{~nm}$ to $443.5 \mathrm{~nm}$ at room temperature while that of F8 increased more significantly from $706.4 \mathrm{~nm}$ to $859.7 \mathrm{~nm}$ within one month. No changes were detected in the zeta potential of both F7 and F8 formulation in all cycles for all time point, which indicated that these two nanosuspensions were rather stable. From the Figure 3, it can be seen that these two nanosuspensions still presented a considerable stability despite their zeta potential being below the critical value of $-20 \mathrm{mV}$. Although there was no difference of zeta potential in both formulations in the stability, F7 formulation had better storage stability than F8 formulation because the particle size was smaller in F7 formulation. Considering the results of the DoE, F7 formulation was chosen as optimum formulation and in vitro studies were conducted with this formulation.

\subsection{Lyophilization of optimum formulations}

As a result of the PS, PDI, and ZP measurements, F7 formulation (CsA:HPMC:Soluplus: 1 :1:1:0.5), which was decided as the optimum formulation, was lyophilized as described in section 4.5.3 and obtained lyophilised nanosuspension was used for further characterization studies.

\subsection{Redispersibility}

The redispersibility index (RDI\%) of lyophilised nanosuspension are shown in Table 3.

Table 3. Data of solubility and RDI\% for CsA, physical mixture, and lyophilised CsA nanosuspension.

\begin{tabular}{lccc}
\hline Formulation & Mannitol ratio (\%) & Solubility $(\mathbf{m g} / \mathbf{m L})$ & RDI \% \\
\hline CsA coarse powder & - & $6.48 \pm 0.88$ & - \\
CsA nanosuspension & 1 & $13.80 \pm 2.14$ & 127.8 \\
\hline
\end{tabular}


The results of redispersibility index percentage showed that the lyophilised nanosuspension agglomerates stabilized with HPMC and Soluplus ${ }^{\circledR}$ combination had almost ideal redispersibility with $127.8 \%$. This value was close to $100 \%$, indicating that there is no agglomeration and particle size growth in the nanosuspension after lyophilization, and that the cryoprotectant is a suitable for formulation. If this value is less than $100 \%$; the cryoprotectant is a solvent for the nanosuspension and causes a reduction in the particle size [20].

\subsection{Differential scanning calorimetry}

The results of Differential scanning calorimetry (DSC) analyses of CsA coarse powder, HPMC, Soluplus ${ }^{\circledR}$, mannitol, physical mixture, and lyophilised nanosuspension are shown in Figure 4.

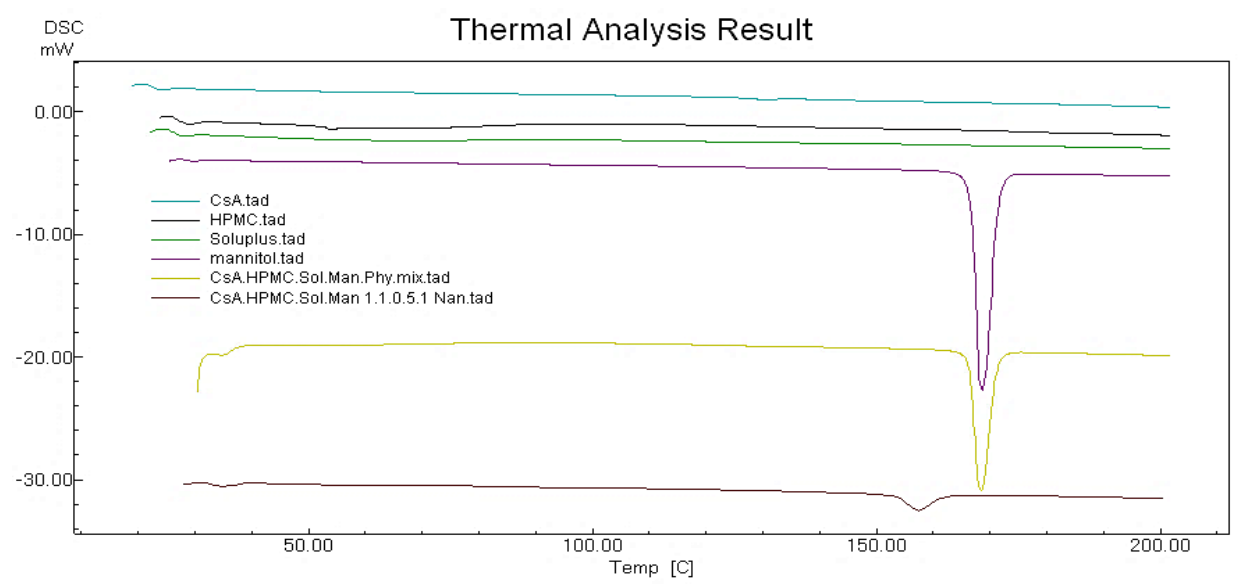

Figure 4. DSC curves of (blue) CsA, (dark blue) HPMC, (green) Soluplus ${ }^{\circledR}$, (pink) Mannitol, (yellow) physical mixture, and (red) lyophilised CsA nanosuspension.

As revealed in the DSC thermogram, the pure CsA powder exhibited an endothermic peak at $130.74{ }^{\circ} \mathrm{C}$. In the physical mixture containing CsA, HPMC, Soluplus ${ }^{\circledR}$, and mannitol, the melting points of these particles did not change as expected. However, the melting point of CsA in the nanosuspension formulations shifted from $130.74^{\circ} \mathrm{C}$ to $129.75^{\circ} \mathrm{C}$. The shift in the nanocrystal was less noticeable. This indicated that the melting point of CsA could be influenced by excipients in the formulation such as stabilizers and criyoprotectant or high pressure which was applied to the particles during microfluidization process. Similar observations were reported in many other nanosuspension formulation studies $[34,38]$ and this difference is not significant.

\subsection{X-Ray diffractometry}

The crystal properties of CsA was investigated by X-Ray diffractometry (X-RD). The diffractogram of lyophilised CsA nanosuspension indicated that CsA coarse powder was in amorphous form and was not changed in the nanosuspension after formulation preparation steps (Figure 5).

A

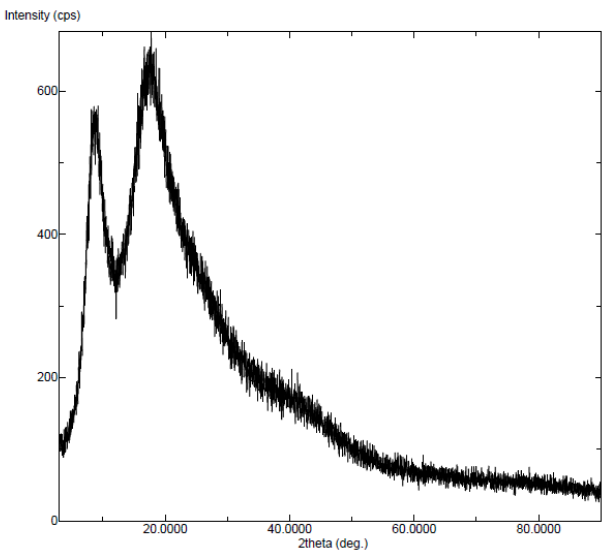

B

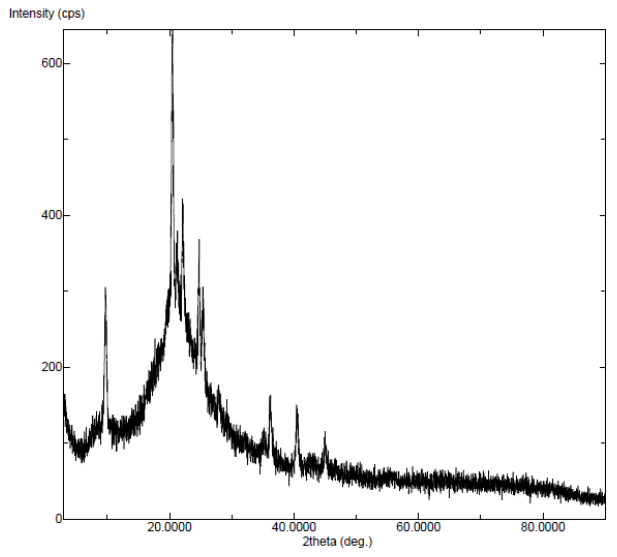

Figure 5. X-ray diffractometry spectra of CsA (A) and lyophilised CsA nanosuspension (B). 


\subsection{Fourier transform infrared spectrophotometry}

Fourier transform infrared spectrophometry (FTIR) measurements were conducted to assess the possible changes in the nanosuspension formulation after microfluidization. FTIR spectrums of CsA coarse powder, HPMC, Soluplus ${ }^{\circledR}$, mannitol, physical mixture, and lyophilised CsA nanosuspension are displayed in Figure 6.

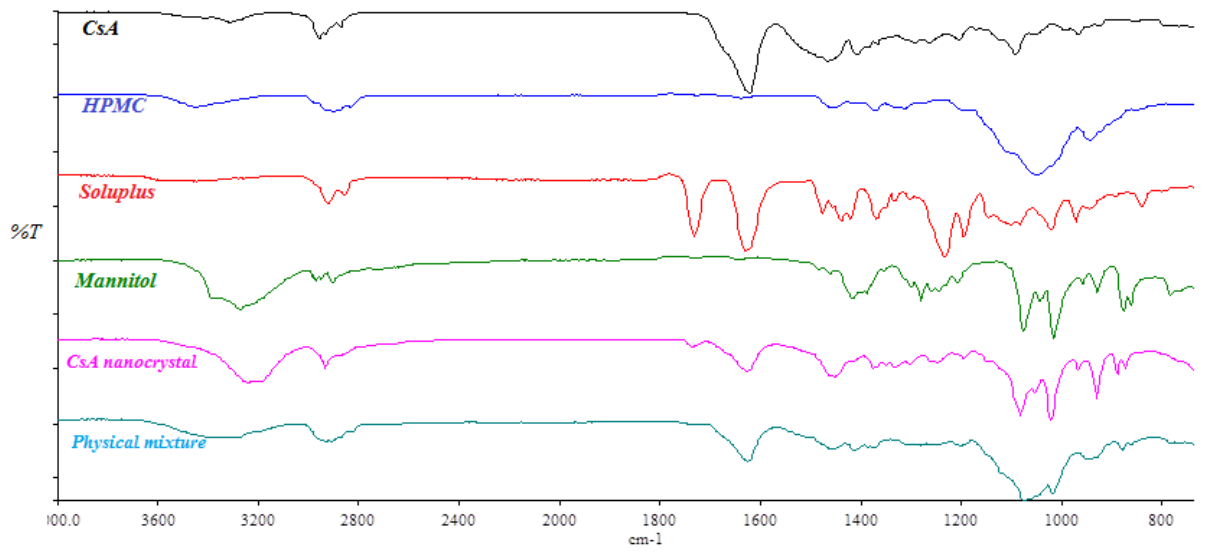

Figure 6. FTIR spectra of CsA coarse powder, excipients, physical mixture, and lyophilised CsA nanosuspension.

The characteristic absorption peaks of raw CsA at 1093, 1466, 1623, and $2959 \mathrm{~cm}^{-1}$ were related to the special chemical structure. FTIR spectra of HPMC showed characteristic absorption bands at 944, 1051, 2904, and $3451 \mathrm{~cm}^{-1}$, while spectra of Soluplus ${ }^{\circledR}$ at 1732, 1630, 1233, and $1195 \mathrm{~cm}^{-1}$. For mannitol, the main absorption peaks were at 878, 1016, 1077, and $3277 \mathrm{~cm}^{-1}$. The spectrums of physical mixture and lyophilised CsA nanosuspension presented all peaks of CsA coarse powder and other excipients.

\subsection{Morphological studies}

The morphological analysis was performed by Scanning electron microscopy (SEM) and the images are shown in Figure 7.
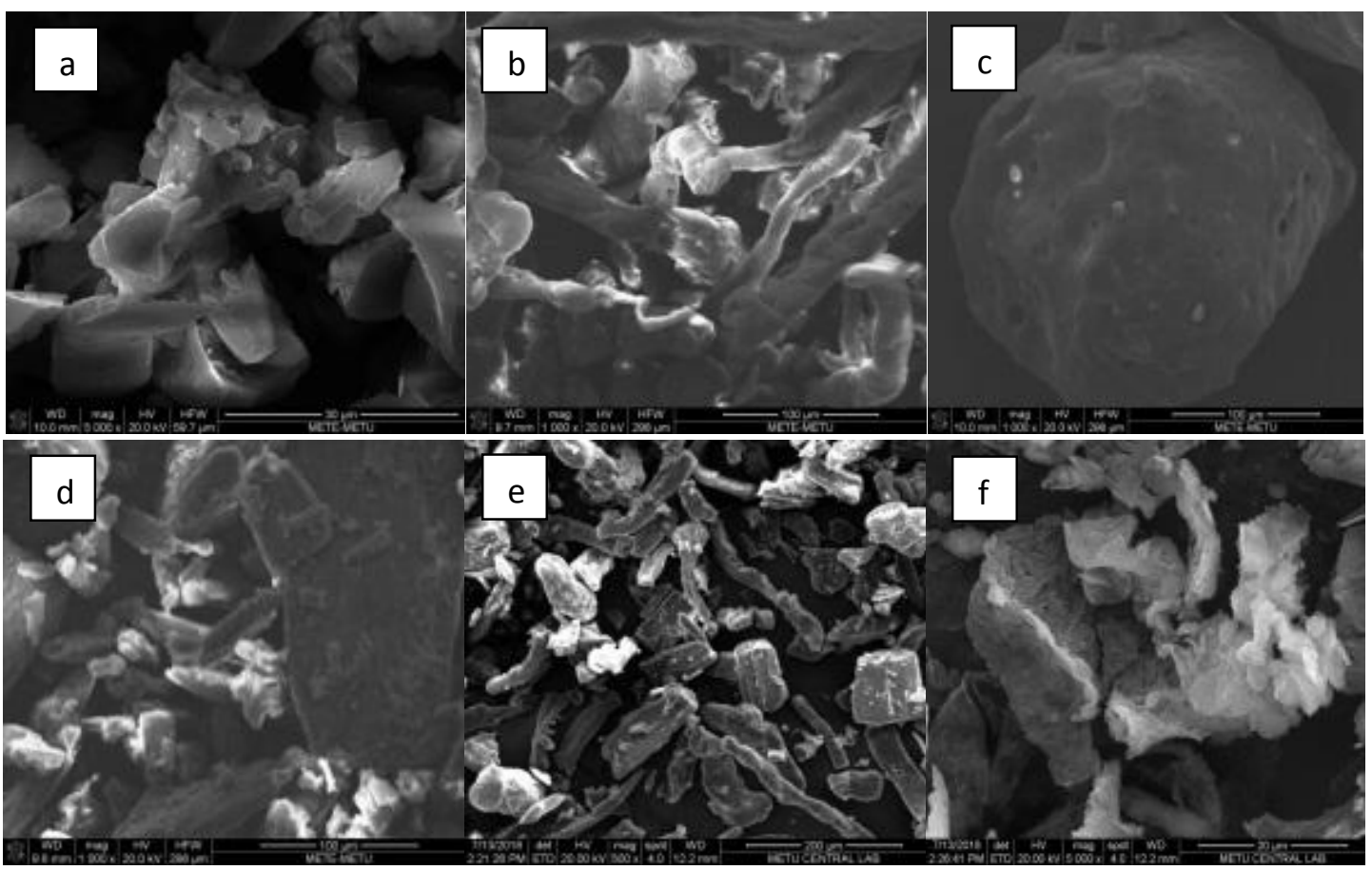

Figure 7. Scanning electron microscopy images of (a) pure CsA, (b) HPMC, (c) Soluplus ${ }^{\circledR}$, (d) Mannitol, (e) physical mixture, and (f) lyophilised CsA nanosuspension. 
SEM image of physical mixture showed that the shapes of the substances were contained in the component clearly. From the SEM images, it was observed that the CsA coarse particles were close to the rod shape. After the CsA nanosuspension was obtained, there appeared to be a round-like change in surface appearance of between 350 and $500 \mathrm{~nm}$ particle size. The modified shape may be due to the coating of the CsA particles with a stabilizing layer and the high pressure applied during the nanosuspension production process [12].

\subsection{Solubility}

The saturation solubility of CsA coarse powder and lyophilised CsA nanosuspension in water at $37^{\circ} \mathrm{C}$ was $6.48 \pm 0.88$ and $13.80 \pm 2.14 \mathrm{mg} / \mathrm{mL}$, respectively (Table 3). The solubility of CsA nanosuspension was 2.13 fold greater than that of coarse CsA. These results indicated that nanosuspension could be effective in improving the solubility of CsA. Also, it could be predicted that the improvement in solubility has the potential to increase the dissolution and then enhancing bioavailability of BCS Class II drugs, such as CsA [11, 38].

\section{CONCLUSION}

CsA nanosuspension was succesfully prepared by using high pressure homogenization method with HPMC and Soluplus ${ }^{\circledR}$. The type of stabilizers (HPMC, Soluplus ${ }^{\circledR}$, and their combination), stabilizer ratios $(1: 0.5,1: 0.25)$ and number of cycles $(5,10,15$, and 30) affected particle size and zeta potential values of nanosuspensions. These effects were investigated using Design Expert ${ }^{\circledR}$ to achieve optimum formulation parameter (combination ratios) and process parameter (number of cycles). Smaller particle size and higher zeta potential was obtained with HPMC:Soluplus ${ }^{\circledR}$ (1:0.5) after 30 homogenization cycles in F7 formulation and further studies were performed with this formulation. The results of our current study demonstrated that the lyophilised CsA nanosuspension had small particle size with round-like surface morphology. After characterization studies, it was observed that no substantial changes occured in physicochemical properties of CsA after high pressure homogenization. The obtained CsA nanosuspension exhibited a remarkable increase (approximately 2-fold) in solubility according to the coarse CsA powder. HPMC-Soluplus ${ }^{\circledR}$ stabilized CsA nanosuspension could be a promising strategy to enhance dissolution and oral bioavailability of CsA.

\section{MATERIALS AND METHODS}

\subsection{Materials}

CsA was a gift sample from Deva Drug Company (Turkey). Polyvinylcaprolactam-polyvinylacetatepolyethyleneglycolgraftcopolymer (Soluplus ${ }^{\circledR}$ ), Poloxamer 188 (Lutrol ${ }^{\circledR}$ F68), and Poloxamer 407 (Kolliphor ${ }^{\circledR}$ P407) were gifted from BASF (Germany). Hydroxypropyl methylcellulose (HPMC) was purchased from Colorcon (USA). D(-) Mannitol and Sodium Dodecyl Sulfate (SDS) were purchased from Merck (Darmstadt, Germany). Polyvinylpyrrolidone K30 (PVP K30) and D-a-Tocopherol polyethylene glycol 1000 succinate (Vitamin E TPGS) was purchased from Sigma Aldrich (USA). All other ingredients used were of analytical grade.

\subsection{Selection of stabilizer types and stabilizer ratios}

In the preformulation studies, firstly stabilization agents were tried seperately and then combined with more than one stabilizer for optimum stabilization. In the development of nanosuspension, Polyvinylpyrrolidone (PVP) K-30, Hydroxypropylmethylcellulose (HPMC), and Soluplus ${ }^{\circledR}$ were used as polymeric stabilizers and Sodium dodecyl sulfate (SDS), Poloxamer 188, Poloxamer 407, and D-a-Tocopherol polyethylene glycol 1000 succinate (Vitamin E TPGS) were used as surfactants stabilizers. In the formulations, the active substance: stabilizer ratio was selected as 1:1, 1:2 and 1:4. Particle size (PS), particle size distribution (PDI), and zeta potential (ZP) measurements were performed at the beginning (at initial), after one week, and after one month after preformulation studies.

The nanosuspensions prepared with HPMC were found to be between $1900 \mathrm{~nm}$ and $900 \mathrm{~nm}$ particle size after 30 homogenization cycles, which the increased polymer ratio caused the increased particle size values. In all ratios and after all homogenization cycles, PDI values were found to be 0.4 and below, and ZP was found to be around $-15 \mathrm{mV}$, and there was no significant change in PS, PDI, and ZP after one week and one month. In the nanosuspension prepared with PVP, it was found that PVP was not a suitable stabilizer in the microfluidization method for CsA nanosuspension, since a milk-like image was formed even after several 
homogenizations. While the PS was found to be about $1400 \mathrm{~nm}$ and $800 \mathrm{~nm}$ in the formulations with Poloxamer 188 and Poloxamer 407 respectively, particle growth was observed over time in one month in these two formulations. In the formulations prepared with SDS, it was found that CsA was dissolved in three ratios and 1:1 ratio was also high for dissolution of CsA. In the formulations prepared with Soluplus ${ }^{\circledR}$, while the PS was around $200 \mathrm{~nm}$ even after five homogenization and the PDI values were around 0.8 and high. In addition, ZP values of all homogenization cycles in all ratios could not be measured and this result $(0 \mathrm{mV})$ was quite lower than the accepted values $(-20 \mathrm{mV})$. In formulations prepared with Vitamin E TPGS, PS values were between $700-800 \mathrm{~nm}$ after 30 passes, while $\mathrm{ZP}$ values were around $-5 \mathrm{mV}$ and low just like Soluplus ${ }^{\circledR}$.

At the end of preliminary studies, it was thought that the particles would become smaller by Soluplus ${ }^{\circledR}$ and zeta potential values could be increased and better stabilization would be achieved by HPMC. HPMC and

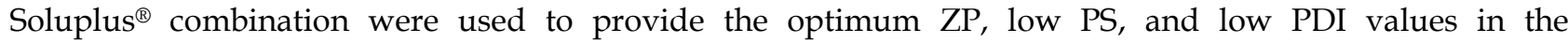
nanosuspension formulation.

\subsection{Preparation of CsA nanosuspension with high pressure homogenization method}

CsA nanosuspension was prepared using high pressure homogenization method. Microfluidics LV1 (Microfluidizer® Processors, USA) with a Z-type $84 \mu \mathrm{m}$ chamber was used for this method. Firstly, different stabilizers (HPMC and Soluplus ${ }^{\circledR}$ ) and their different ratios (CsA:stabilizer 1:1, 1:2, and 1:4) were used to stabilize the nanosuspension separately and then their combination (CsA:HPMC:Soluplus ${ }^{\circledR}$ 1:1:0.5 and 1:1:0.25) was used. The DoE approach was used to determine the CsA:HPMC:Soluplus ${ }^{\circledR}$ ratio to be used to achieve optimum particle size and stabilization, and the effect of the Soluplus ${ }^{\circledR}$ ratio was investigated by DoE. For this purpose, two different CsA:HPMC:Soluplus ${ }^{\circledR}$ (CsA:HPMC:Soluplus ${ }^{\circledR}$ 1:1:0.5 and 1:1:0.25) ratios and four different homogenization cycles (5-10-15-30 cycles) were selected as independent variables and PS,PDI, and ZP results were selected dependent variables. For DoE analysis, two combined stabilizer ratios and four homogenization cycles experiments were carried out with two replicate. The stabilizers and their ratios used for formulation are given in Table 4.

Table 4. Composition of CsA Nanosuspension.

\begin{tabular}{cccc}
\hline $\begin{array}{c}\text { Formulation } \\
\text { Code }\end{array}$ & $\begin{array}{c}\text { Cyclosporine A } \\
(\% \mathbf{w} / \mathbf{w})\end{array}$ & $\begin{array}{c}\text { HPMC } \\
(\mathbf{\%} \mathbf{w} / \mathbf{w})\end{array}$ & $\begin{array}{c}\text { Soluplus }^{\circledR} \\
(\mathbf{\%} \mathbf{w} / \mathbf{w})\end{array}$ \\
\hline F1 & 1.0 & 1.0 & - \\
F2 & 1.0 & 2.0 & - \\
F3 & 1.0 & 4.0 & - \\
F4 & 1.0 & - & 1.0 \\
F5 & 1.0 & - & 2.0 \\
F6 & 1.0 & - & 4.0 \\
F7 & 1.0 & 1.0 & 0.5 \\
F8 & 1.0 & 1.0 & 0.25 \\
\hline
\end{tabular}

The shematic presentation of the preparation steps for CsA nanosuspension is shown in Figure 8. For preparation of formulation, different amounts of stabilizers were dissolved in deionized water at room temperature. $1 \%(\mathrm{w} / \mathrm{w})$ of CsA was dispersed in this stabilizer solution under the magnetic stirrer at $1000 \mathrm{rpm}$ for 20 minutes. The UltraTurrax (Heidolph, SilentCrusher M) (at $15.000 \mathrm{rpm}-10$ minutes) was used to reduce particle size of coarse suspension to prevent high pressure homogenizer from chamber blockage. Finally, this coarse suspension was transferred into Microfluidics LV1 and homogenized for different cycles (5-10-15, and 30 cycles) at 30.000 psi process pressure.

\subsection{Preparation of physical mixture}

The physical mixtures were prepared by mixing the CsA coarse powder for about 5 minutes at the same rate as the stabilizers used in the nanosuspension formulations.

\subsection{Characterization studies of optimized CsA nanosuspension}

The PS, PDI, and ZP measurements were performed to select the most appropriate nanosuspension and an optimum formulation was selected for further characterization studies. Optimization was based on PS, PDI, and ZP measurement and a formulation which was considered to be optimized was lyophilized. Scanning Electron Microscopy (SEM), Differential Scanning Calorimetry (DSC), Fourier Transform Infrared Spectroscopy (FTIR), and X-Ray Diffraction (XRD) studies were performed in this lyophilised nanosuspension formulation. 


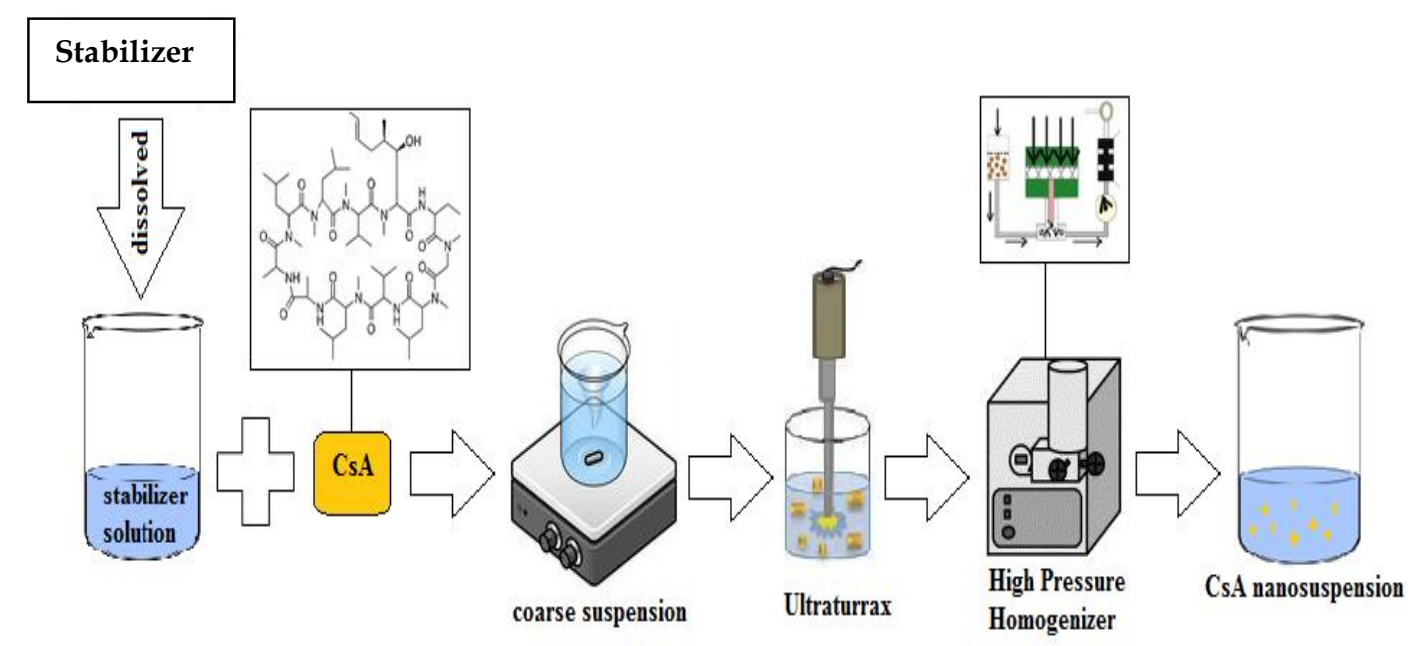

Figure 8. The shematic presentation of the preparation steps for CsA nanosuspension.

\subsubsection{Particle size, particle size distribution and zeta potential measurement}

The PS, PDI, and ZP of nanosuspensions were measured at $25 \pm 2{ }^{\circ} \mathrm{C}$ by dynamic light scattering using Malvern ZetaSizer-Nano ZS (Malvern Instruments Limited, UK). Briefly, $750 \mu \mathrm{L}$ of the nanosuspension samples were dropped into the cuvettes and $750 \mu \mathrm{L}$ of distilled water were added. Each sample was measured in triplicate and average values were determined.

\subsubsection{Short term physical stability}

Short term physical stability studies of CsA nanosuspensions stabilized with all stabilizers and all stabilizer ratios were performed at $25 \pm 2{ }^{\circ} \mathrm{C}$. The fresh prepared CsA nanosuspensions were kept at closed vial at room temperature. PS, PDI, and ZP values were measured at the time points of zero (at initial), one week, and one month.

\subsubsection{Lyophilization of optimum nanosuspension formulation}

Drying of nanosuspensions is important for long-term stability and solid dosage forms which are easy to administer to the patient in tablet or capsule for oral administration. After the PS, PDI, and ZP measurements, the lyophilization (freeze drying) process was applied for optimum nanosuspension formulation. For the lyophilization process, about $2 \mathrm{~g}$ of the nanosuspension were frozen at $-80^{\circ} \mathrm{C}$ for 2 hours and freeze drying was carried out at $-50^{\circ} \mathrm{C}$ under 0.021 mbar pressure for 48 hours (Christ Alpha 1-2 LD Plus, France). The ratio of mannitol to be used as cryoprotectant in the prepared nanosuspension was selected as CsA: mannitol ratio of $1: 1 \mathrm{w} / \mathrm{w}$.

\subsubsection{Redispersibility}

The redispersibility of lyophilised nanosuspension was expressed as redispersibility index percentage (RDI\%) as given below (Eq. 4) [39]:

$$
\text { RDI } \%=\frac{Z \text { average }}{Z \text { average }(0)} \times 100
$$

Where $Z_{\text {average (0) }}$ is the mean particle size value of the nanosuspension (before lyophilization) and $Z_{\text {average }}$ is the mean particle size value of reconstituted nanosuspensions after rehydration of the lyophilised nanosuspension. Lyophilised nanosuspension was dispersed in few milliliters of distilled water and was shaken for $70 \mathrm{~s}$ by vortex before being transferred in cuvettes. RDI values close to $100 \%$ indicate that the particle sizes are similar to the initial particle sizes after rehydration [20].

\subsubsection{Differential scanning calorimetry}

DSC was performed to investigate the effect of stabilizers, prepared physical mixtures and nanocrystal on the internal structure of the system during preparation of the nanosuspensions. DSC is an important 
analysis to obtain information on possible interactions between active ingradients and excipients, depending on changes in endothermic or exothermic peaks after the process. Thermal properties of CsA, stabilizers, physical mixtures, and lyophilized CsA nanosuspension were examined by DSC (DSC-60, Shimadzu Scientific Instruments, Japan). Firstly, CsA and other excipients were weighed $2 \mathrm{mg}$ and placed into aluminum pans and the pans were closed. Then $2 \mathrm{mg}$ mixtures of CsA and other excipients in a 1: 1 ratio were prepared. Mixtures were also placed into aluminum pans and the pans were sealed. Finally, the lyophilised nanosuspension were weighed $2 \mathrm{mg}$ and the same procedure was repeated. DSC thermograms were obtained by measuring the heating rate of $10^{\circ} \mathrm{C} / \mathrm{min}$ and the temperatures between $25^{\circ} \mathrm{C}$ and $200^{\circ} \mathrm{C}$.

\subsubsection{X-ray diffractometry}

XRD study was performed on lyophilized CsA nanosuspension and CsA coarse powder to detect possible changes in the internal structure of lyophilized CsA nanosuspension. In the analysis, the effect of the high energy applied on the particles during high pressure homogenization and the changes in the internal structure of the nanoparticles were investigated. In XRD analysis, the scan rate was $1^{\circ}$ per minute and the scan range was $2 \theta$ in the range of $3-90^{\circ}$ (RigakuUltima IV, Japan).

\subsubsection{Fourier transform infrared spectrophotometry}

FTIR spectra for nanosuspension formulations, formulation components, and physical mixtures were obtained using Perkin Elmer Spectrum400 FT-IR, FT-NIR (USA). The KBr disc technique was used to make infrared measurements. Measurements were made as $750-4000 \mathrm{~cm}^{-1}$ screening interval and $1 \mathrm{~cm}^{-1}$ discrimination power.

\subsubsection{Morphological studies}

Scanning electron microscopy (SEM) (Quanta 400F, Holland) was used to evaluate the morphological properties of the lyophilised nanosuspension and to compare them to the morphological characteristics of coarse powders and physical mixtures. All samples were coated with gold-palladium before measurement.

\subsection{Solubility Study}

To evaluate the solubility of coarse CsA powder and the lyophilised CsA nanosuspension, equilibrium solubility was determined. Equilibrium solubility measurements were carried out as follows: firstly excessive amounts of CsA powder and the lyophilised optimum formulation were added to distilled water. Samples were put in vials and shaken for 48 hours at $25^{\circ} \mathrm{C}$. Then the samples were filtered through a $0.22 \mu \mathrm{m}$ filter and the CsA concentration was determined by validated UV spectrofotometer at $205 \mathrm{~nm}$.

Acknowledgements: This study was supported by Gazi University Scientific Research Project Foundation (Grant No: 02/2017-14). The authors are thankful to Deva Pharmaceutical Company (İstanbul, Turkey) for providing CsA and BASF for providing Poloxamer 188, Poloxamer 407, and Soluplus ${ }^{\circledR}$. The authors would also like to thanks to Alptug Eren Karakucuk for contribution of DoE.

Author contributions: Concept - N.Ç.; Design - N.Ç., S.G.P.; Supervision - N.Ç.; Resources - N.Ç.. Materials - N.Ç., S.G.P.; Data Collection and/or Processing - N.Ç., S.G.P..; Analysis and/or Interpretation - N.Ç., S.G.P.; Literature Search - N.Ç., S.G.P.; Writing - N.Ç., S.G.P.; Critical Reviews - N.Ç., S.G.P.

Conflict of interest statement: The authors declared no conflict of interest.

\section{REFERENCES}

[1] Guada M, Beloqui A, Kumar MNVR, Carmen Dios-Viéitez VPM, Blanco-Prieto MJ. Reformulating cyclosporine A (CsA): More than just a life cycle management strategy. J Control Release. 2016; 225: 269-282. [CrossRef]

[2] Survase SA, Kagliwal LD, Annapure US, Singhal RS. Cyclosporin A - A review on fermentative production, downstream processing and pharmacological applications. Biotechnol Adv. 2011; 29: 418-435. [CrossRef]

[3] Gao L, Zhang D, Chen M, Duan C, Dai W, Jia L, Zhao W. Studies on pharmacokinetics and tissue distribution of oridonin nanosuspensions. Int J Pharm. 2008; 355: 321-327. [CrossRef]

[4] Müller RH, Runge S, Ravelli V, Mehnert W, Thünemann AF, Souto EB. Oral bioavailability of cyclosporine: Solid lipid nanoparticles (SLN®) versus drug nanocrystals. Int J Pharm. 2006; 317: 82-89. [CrossRef]

[5] Möschwitzer J, Müller RH. Spray coated pellets as carrier system for mucoadhesive drug nanocrystals. Eur J Pharm Biopharm. 2006; 62: 282-287. [CrossRef] 
[6] Wang GD, Mallet FP, Ricard F, Heng JYY. Pharmaceutical nanocrystals. Curr Opin Chem Eng. 2012; 1(2): 102-107. [CrossRef]

[7] Gülsün T, Gürsoy RN, Öner L. Nanocrystal technology for oral delivery of poorly water-soluble drugs. FABAD J Pharm Sci. 2009; 34(1): 55-65.

[8] Junghanns JU, Müller RH. Nanocrystal technology, drug delivery and clinical applications. Int J Nanomedicine. 2008; 3(3): 295-309. [CrossRef]

[9] Santos AM, Carvalho FC, Teixeira DA, Azevedo DL, Barros WM, Gremião MPD. Computational and experimental approaches for development of methotrexate nanosuspensions by bottom-up nanoprecipitation. Int J Pharm. 2017; 524: 330-338. [CrossRef]

[10] Du J, Li X, Zhao H, Zhou Y, Wang L, Tian S, Wang Y. Nanosuspensions of poorly water-soluble drugs prepared by bottom-up technologies. Int J Pharm. 2015; 495: 738-749. [CrossRef]

[11] Oktay AN, Karakucuk A, Ilbasmis-Tamer S, Celebi N. Dermal flurbiprofen nanosuspensions: Optimization with design of experiment approach and in vitro evaluation. Eur J Pharm Sci. 2018; 122: 254-263. [CrossRef]

[12] Karakucuk A, Celebi N, Teksin ZS. Preparation of ritonavir nanosuspensions by microfluidization using polymeric stabilizers: I. A Design of Experiment approach. Eur J Pharm Sci. 2016; 95: 111-121. [CrossRef]

[13] Verma S, Lan Y, Gokhale R, Burgess JR. Quality by design approach to understand the process of nanosuspension preparation. Int J Pharm. 2009; 377: 185-198. [CrossRef]

[14] Fernandes AR, Ferreira NR, Fangueiro JF, Santos AC, Veiga FJ, Cabral C, Silva AM, Souto EB. Ibuprofen nanocrystals developed by $2^{2}$ factorial design experiment: A new approach for poorly water-soluble drugs. Saudi Pharm J. 2017; 25: 1117-1124. [CrossRef]

[15] Wang L, Liu Z, Liu D, Liu C, Juan Z, Zhang N. Docetaxel-loaded-lipid-based-nanosuspensions (DTX-LNS): Preparation, pharmacokinetics, tissue distribution and antitumor activity. Int J Pharm. 2011; 413; 194- 201. [CrossRef]

[16] Möschwitzer J, Achleitner G, Pomper H, Müller RH. Development of an intravenously injectable chemically stable aqueous omeprazole formulation using nanosuspension technology. Eur J Pharm Biopharm. 2004; 58: 615-619. [CrossRef]

[17] Li Y, Wang D, Lu S, Zeng L, Wang Y, Song W, Liu J. Pramipexole nanocrystals for transdermal permeation: Characterization and its enhancement micro-mechanism. Eur J Pharm Sci. 2018; 124: 80-88. [CrossRef]

[18] Medarević D, Djuriš J, Ibrić S, Mitrić M, Kachrimanis K. Optimization of formulation and process parameters for the production of carvedilol nanosuspension by wet media milling. Int J Pharm. 2018; 540: 150-161. [CrossRef]

[19] Huang S, Zhang Q, Li H, Sun Y, Cheng G, Zou M, Piao H. Increased bioavailability of efonidipine hydrochloride nanosuspensions by the wet-milling method. Eur J Pharm Biopharm. 2018; 130: 108-114. [CrossRef]

[20] Toziopoulou F, Malamatari M, Nikolakakis I, Kachrimanis K. Production of aprepitant nanocrystals by wet media milling and subsequent solidification. Int J Pharm. 2017; 533: 324-334. [CrossRef]

[21] Sharma OP, Patel V, Mehta T. Design of experiment approach in development of febuxostat nanocrystal: Application of Soluplus® as stabilizer. Powder Technol. 2016; 302: 396-405. [CrossRef]

[22] Kumar S, Xu X, Gokhale R, Burgess DJ. Formulation parameters of crystalline nanosuspensions on spray drying processing: A DoE approach. Int J Pharm. 2014; 464: 34-45. [CrossRef]

[23] Guo C, Chen Y, Zhu J, Wang J, Xu Y, Luan H, Zhu Z, Hu M, Wang H. Preparation, optimization of intravenous ZL004 nanosuspensions by the precipitation method, effect of particle size on in vivo pharmacokinetics and tissue distribution. J Drug Deliv Sci Technol. 2019; 50: 313-320. [CrossRef]

[24] Lu Y, Wang Z, Li T, McNally H, Park K, Sturek M. Development and evaluation of transferrin-stabilized paclitaxel nanocrystal formulation. J Control Release. 2014; 176: 76-85. [CrossRef]

[25] Zhang H, Hollis CP, Zhang Q, Li T. Preparation and antitumor study of camptothecin nanocrystals. Int J Pharm. 2011; 415: 293- 300. [CrossRef]

[26] Xia D, Quan P, Piao H, Piao H, Sun S, Yin Y, Cui. Preparation of stable nitrendipine nanosuspensions using the precipitation-ultrasonication method for enhancement of dissolution and oral bioavailability. Eur J Pharm Sci. 2010; 40: 325-334. [CrossRef]

[27] Möschwitzer JP. Drug nanocrystals in the commercial pharmaceutical development process. Int J Pharm. 2013; 453: 142- 156. [CrossRef] 
[28] Salazar J, Müller RH, Möschwitzer JP. Performance comparison of two novel combinative particle-size-reduction technologies. J Pharm Sci. 2013; 102 (5): 1636-1649. [CrossRef]

[29] Salazar J, Ghanem A, Müller RH, Möschwitzer JP. Nanocrystals: Comparison of the size reduction effectiveness of a novel combinative method with conventional top-down approaches. Eur J Pharm Biopharm. 2012; 81: 82-90. [CrossRef]

[30] Shegokar R, Müller RH. Nanocrystals: Industrially feasible multifunctional formulation technology for poorly soluble actives. Int J Pharm. 2010; 399: 129-139. [CrossRef]

[31] Gulsun T, Borna SE, Vural I, Sahin S. Preparation and characterization of furosemide nanosuspensions. J Drug Deliv Sci Technol. 2018; 45: 93-100. [CrossRef]

[32] Zong L, Li X, Wang H, Cao Y, Yin L, Li M, Wei Z, Chen D, Pu X, Han J. Formulation and characterization of biocompatible and stable I.V. itraconazole nanosuspensions stabilized by a new stabilizer polyethylene glycolpoly( $\beta$-Benzyl-1-aspartate) (PEG-PBLA). Int J Pharm. 2017; 531: 108-117. [CrossRef]

[33] Attari Z, Bhandari A, Jagadish PC, Lewis S. Enhanced ex vivo intestinal absorption of olmesartan medoxomil nanosuspension: Preparation by combinative technology. Saudi Pharm J. 2016; 24: 57-63. [CrossRef]

[34] Hong C, Dang Y, Lin G, Yao Y, Li G, Ji G, Shen H, Xie Y. Effects of stabilizing agents on the development of myricetin nanosuspension and its characterization: An in vitro and in vivo evaluation. Int J Pharm. 2014; 477: $251-260$. [CrossRef]

[35] Sinha B, Müller RH, Moschwitzer JP. Systematic investigation of the cavi-precipitation process for the production of ibuprofen nanocrystals. Int J Pharm. 2013; 458: 315- 323. [CrossRef]

[36] Keck CM, Müller RH. Drug nanocrystals of poorly soluble drugs produced by high pressure homogenisation. Eur J Pharm Biopharm. 2006; 62: 3-16. [CrossRef]

[37] Wang Y, Zheng Y, Zhang L, Wang Q, Zhang D. Stability of nanosuspensions in drug delivery. J Control Release. 2013; 172: 1126-1141. [CrossRef]

[38] He J, Han Y, Xu G, Yin L, Neubi MN, Zhou J, Ding Y. Preparation and evaluation of celecoxib nanosuspensions for bioavailability enhancement. RSC Adv. 2017; 7: 13053-13064. [CrossRef]

[39] Yue PF, Li Y, Wan J, Yang M, Zhu WF, Wang CH. Study on formability of solid nanosuspensions during nanodispersion and solidification: I. Novel role of stabilizer/drug property. Int J Pharm. 2013; 454: 269 - 277. [CrossRef]

This is an open access article which is publicly available on our journal's website under Institutional Repository at http://dspace.marmara.edu.tr. 